\title{
Network analysis of the sick-pig commodity chain in Northern Vietnam: Risk of disease dissemination
}

\author{
Mai Ngoc Hoang ${ }^{1 *}$ Phuong Thi Nguyen ${ }^{1}$ Hanh Quang Han ${ }^{1}$ \\ Tien Dinh Nguyen ${ }^{1}$ Ton Dinh $\mathrm{Vu}^{1}$ Marisa Peyre ${ }^{2,3}$
}

\section{Keywords}

Swine, food supply chain, risk assessment, animal diseases, fraud, Vietnam

Submitted: 19 March 2018

Accepted: 19 December 2019

Published: 29 June 2020

DOI: $10.19182 /$ remvt.31872

\begin{abstract}
Summary
A study was carried out between January and July 2016 to investigate the sickpig trade network which is believed to have been operating in Northern Vietnam for decades. From early 2015, many warnings about the existence of this illegal network have been published in local newspapers, causing great concern among consumers and authorities. The aim of this study was to investigate the commodity chain to identify the trade network, evaluate the risk of disease dissemination, and propose preventive solutions. The results showed that the sick-pig commodity chain included farmers, middlemen, slaughterhouses and consumers in the three studied districts (Van Lam, Van Giang and My Hao, in Hung Yen Province). The qualitative risk assessment determined that middlemen and slaughterhouses were the main actors in this uncontrolled chain. Appropriate administrative regulations, regardless of the importance of these actors, would be crucial to limit negative effects of sick-pig products. Furthermore, proper intervention would remove threats to other farms and long-term effects on human health.
\end{abstract}

- How to quote this article: Hoang M.N., Nguyen P.T., Han H.Q., Nguyen T.D., Vu T.D., Peyre M., 2020. Network analysis of the sick-pig commodity chain in Northern Vietnam: Risk of disease dissemination. Rev. Elev. Med. Vet. Pays Trop., 73 (2): 61-70, doi : 10.19182/remvt.31872

\section{INTRODUCTION}

In Vietnam, swine production plays a vital role in the rural economy. Pork accounts for $74-80 \%$ of total meat consumption (Nga et al., 2013). Over the last decade, overall pork consumption has increased by $7 \%$ a year and the swine population is expected to reach 34.7 million in 2020, i.e. an increase of 7.6 million compared to 2011 (Department of Livestock Production; MARD, 2017). High pork consumption is reflective of an eating tradition. For the majority of Vietnamese families, pork is the favorite protein source, easily cooked for both regular dishes in daily meals and special dishes at annual festivals. In addition, pork is a crucial food to process numerous Vietnamese specialties, e.g. fermented pork rolls (nem chua), rousong or pork floss (ruốc), pork jerky (thịt khô) and so on.

However, the swine commodity chain has been facing many issues related to disease emergence and contagious expansion. Over recent

\footnotetext{
1. Faculty of Animal Science, Vietnam National University of Agriculture, Trau Quy, Vietnam.

2. CIRAD, UMR ASTRE, F-34398 Montpellier, France.

3. ASTRE, Univ Montpellier, CIRAD, INRAE, Institut Agro, Montpellier, France.

* Corresponding author

Email: mai.hoangngoc@uq.net.au; phone: 84796200006
}

decades, the pig industry in Vietnam has dealt with serious threats and losses caused by major infectious diseases such as porcine reproductive and respiratory syndrome (PRRS), classical swine fever (CSF), foot-and-mouth disease (FMD) (Pham et al., 2017). The hazards threatening the sustainability of the pork value chain consist not only of spontaneous diseases which emerge seasonally, but also, more alarmingly, of out-of-control infectious diseases which may rapidly contaminate areas neighboring the infected territory, leading to the explosion of outbreaks. An important disease-spreading case was recorded in 2006-2007, in which Vietnam was evidenced as a 'victim' of PRRS virus dissemination, originally from China in 2006, and recurring in 2007 (Feng et al., 2008). According to the World Organisation for Animal Health (OIE, 2007), the consequence led to 44 highly pathogenic PRRS (HP-PRRS) outbreaks in Vietnam by August 2007; allegedly Northern Vietnam was initially exposed during March-May and later, during June-July, the outbreaks concerned Southern provinces. Total infected pigs were 44,000 with a mortality rate of approximately $10 \%$ (OIE, 2007). Since then, HP-PRRS has been classified in the group of endemic swine diseases in Vietnam and it has frequently recurred (Nguyen, 2013).

The uncontrolled spread of infectious germs leads to a vast array of weighty consequences, including widespread outbreaks and huge economic losses. As reported by OIE in 2006, before invading Vietnam, PRRS virus has swept through China with 445 outbreaks, affecting two million pigs, of which 400,000 died (Nguyen, 2013; Tian et al., 
2007). These outbreaks have been assumed to cause huge economic damages in China given the average swine death rate of $19.68 \%$ (Tian et al., 2007). In other countries, similar reports have been recorded. For example, during the PRRS outbreaks in Netherlands in early 1991, a study on 91 PRRSV-positive farms evaluated the average economic loss per sow per year at roughly 65 pounds (based on fixed price for piglets) (Brouwer et al., 1994). In the United States of America, total expenses on disease-control campaigns against PRRS outbreaks occurring in 1987 were estimated at over 761 million dollars (Johnson et al., 2005).

In reality, the dissemination of swine infectious diseases probably resulted from a multitude of reasons, such as the contamination via infected carrying vehicles (e.g. trucks, motorbikes), the introduction of disease to healthy herds via artificial insemination (Althouse and Rossow, 2011), the cross contamination via human activities. Nevertheless, improper treatment and disposal of sick, dying or dead animals is the critical starting point of disease spread. In Vietnam, the trading of diseased, injured, dying and dead animals has become a common practice (Delabouglise et al., 2016). Several works confirm that farmers' behavior with regard to poultry sickness/death includes both proper disposal (burying, burning, etc.) and improper use (such as quickly selling off) (Desvaux and Figuié, 2011; Desvaux et al., 2016). Baudon et al. (2017) make a similar observation on swine movements in Northern Vietnam. Nevertheless, it remains unclear if this value chain is properly organized or limited to crises. The informal trade of diseased or dead pigs causes not only a potential risk of disease contamination to other swine farms, but also hazards of both virus/bacteria transmissions to humans and consumption of residual antibiotics in pork, which has raised a big concern about food safety (Kim et al., 2013).

The vague knowledge on the trading activities of sick/dead pigs prevents veterinary authorities from conducting proper surveillance and preventing risks to animal and human health. The aim of this study was to characterize the practices of the sick/dead pig trade in Vietnam through a network analysis approach, and to provide recommendations for its management.

\section{MATERIALS AND METHODS}

\section{Study area}

This study was conducted in the villages of Me So (Van Giang District), Dinh Du (Van Lam District) and Nhan Hoa (My Hao District), Hung Yen Province, Northern Vietnam (Figure 1). Hung Yen has the highest pig population density and number of industrial pig farms in the Red River Delta (RRD). The province holds one urban city and nine suburban districts, located at the center of RRD next to three major markets (Hanoi, Hai Phong and Quang Ninh), where pork is highly consumed as a result of increased industrialization and urbanization. The trading of sick pigs has been reported in a previous study conducted in Hung Yen Province, but not at district level (Baudon et al., 2017). According to statistical data provided by local state veterinarians (regularly used for veterinary campaigns, not officially accessible to the public), in 2016, there were 447 swine farms located in seven agricultural districts, i.e. 32 farmsteads (1000-5000 fattening pigs and/or 500-1000 sows per production cycle), 105 large farms (100-900 fattening pigs and/or 20-500 sows per production cycle) and 310 small farms (fewer than 100 fattening pigs and/or 20 sows per production cycle). In the three studied districts there were 255 swine farms that accounted for $57 \%$ of total swine farms in the whole province. The communes and villages were selected based on the density of pig farms, and the diversity of swine farming systems and trading practices.

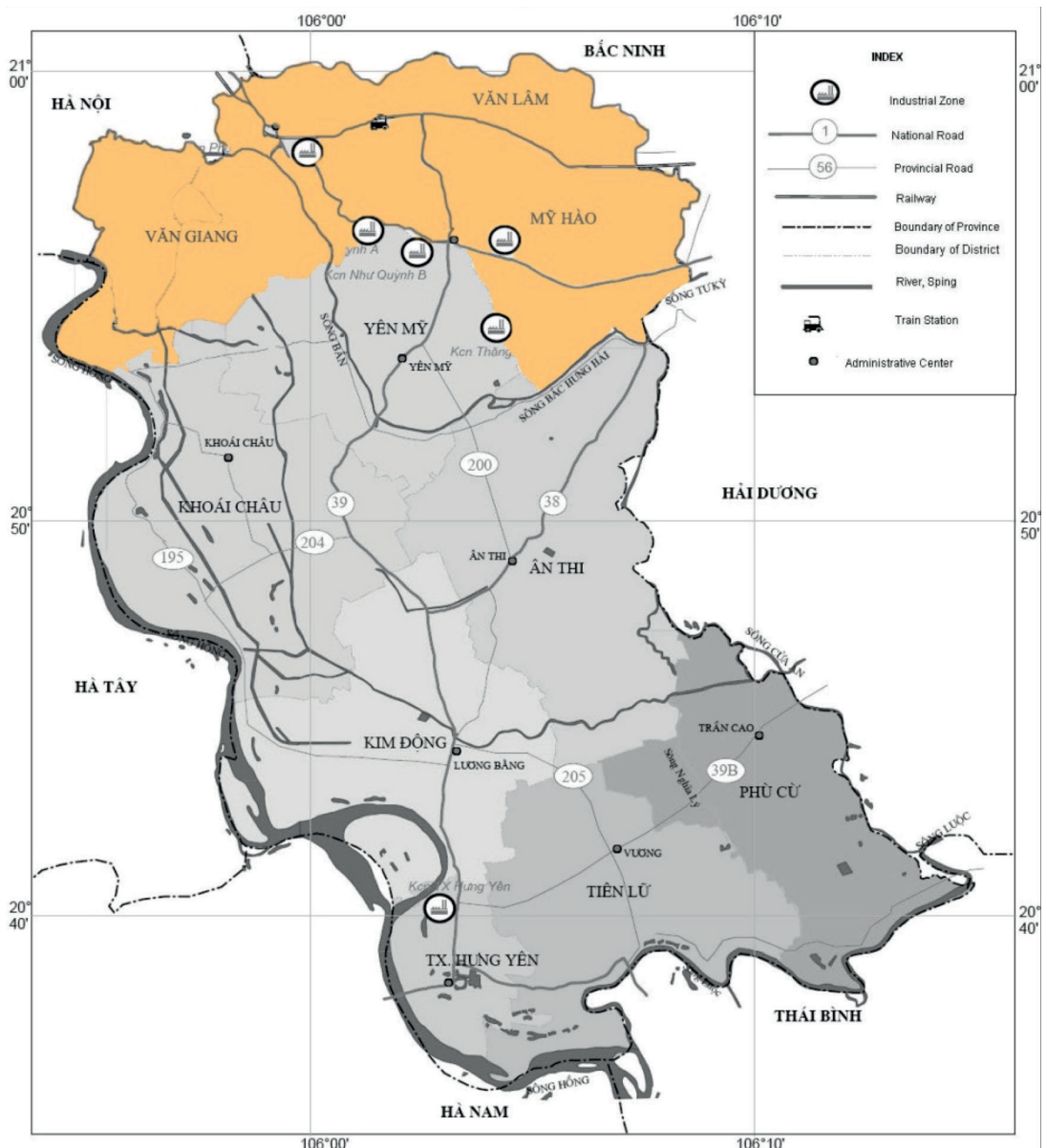

Figure 1: Studied area in Hung Yen Province in Vietnam: Van Giang, Van Lam and My Hao districts are highlighted in yellow. 


\section{Study sample}

We categorized the pig farms in two groups: i) small farms (fewer than 20 sows and/or 100 fattening pigs per production cycle), and ii) large farms (more than 20 sows and/or 100 fattening pigs per production cycle). Due to the limited budget of this project, the number of surveys was down scaled compared to the actual number of farming households. Based on the advice of local authorities and state veterinarians, a proportional down-scaling to 100 households prioritized the typicality of sample type and farming size. We thus randomly selected 65 small farms and 35 large farms, which reflected the actual ratio of small to large farms in the studied sites. This selection of samples excluded the farmsteads because they were not willing to answer questions on sick pigs. Middlemen and slaughterhouses were selected using a snowball sampling approach, i.e. the trader contacts provided by the interviewed farmers were included in the sampling frame. Later, the slaughterhouses were categorized into small and large depending on their operative scale. The selection also depended on the persons' willingness to participate in the study and provide information.

\section{Data collection}

Farmers were interviewed using participatory approaches (semistructured interviews) to collect information on: i) swine production, ii) prevention and treatment of swine diseases, iii) farmers' behavior toward diseased and dead pigs, and iv) awareness of disease transmission hazards caused by the sick-pig commodity chain.

Structured questionnaires were used to collect information on diseased and dead pig transportation pathways from both farmers and traders. Data were collected on: i) marketing and trading activities, ii) socioeconomic factors behind the marketing process, and iii) awareness of the risks of disease transmission.

Owners and/or slaughterhouse workers were interviewed using semi-structured interviews to collect data on: i) slaughterhouses and slaughtering activities, ii) trading activities, and iii) awareness of the risks of infectious dissemination.

\section{Data management and analysis}

Both quantitative and qualitative data were entered in an Excel database. Inconsistent and unreliable information collected during interviews were eliminated. Data reliability was checked using both several 'tricky' repetitive questions on sensitive subjects (e.g. practices on sick/dead pigs, pricing concern), and interviewers' experience-based assumption and expertise consultancy (e.g. the heads of villages, state veterinarians, professors in swine production). When necessary, the interviewees were contacted again by phone to clarify conflicting or unclear information. A model of the swine value chain network, including pig movements between actors, was developed with CmapTools freeware (Daley et al., 2007). CmapTools allows to build concept maps and visualize the influence between different actors of certain networks.

\section{RESULTS}

\section{Sick-pig value chain: a very well-structured system A multi-actor well-organized network}

Similar answers from farmers, middlemen and butchers confirmed the existence and operation of an organized sick-pig value chain system in all studied districts. The sick-pig commodity chain involved farmers, specific middlemen, slaughterhouses and retailers. Healthy and sick-pigs trade networks operated separately but several actors were found to be present in both. The majority of sick pork and by-products ended in fish and carnivorous animal farms, and was selectively mixed with healthy products and sold to restaurants and/or cafeterias of companies. Pig skins were collected by leather and dried skin processing factories, where the health status of the pigs did not cause significant problems. Within this network, there were three 'producing' actors and two 'consuming' actors involved in both the healthy and the sick-pig trades, namely large farms, small farms, small slaughterhouses, common restaurants, and many cafeterias of companies in industrial zones (Figure 2).

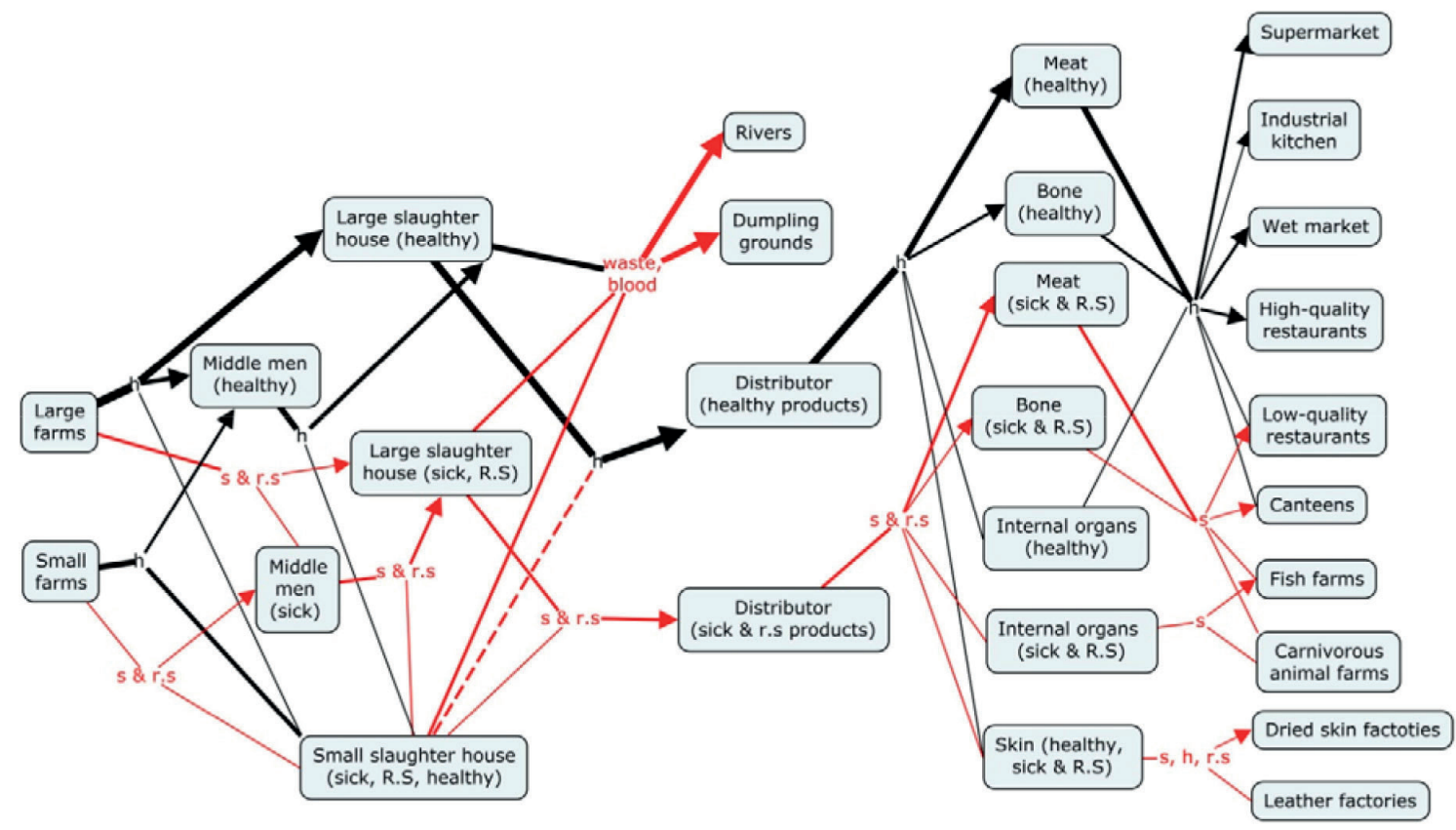

Figure 2: Swine and swine-product network in Hung Yen Province in Vietnam: red lines: sick pigs or sick-pig products; black lines: healthy pigs or healthy-pig products; line thickness: relative importance of a trade route; dotted line: potential trade between actors; $s=$ sick pigs; $r . s=$ reformed sows 
Key actors in chain linking were sick-pig middlemen, slaughterhouse workers and owners, and sick-meat retailers who had built the frame of the sick-pig trade network. To some extent, this network was not considered entirely illegal because materials were not only sick and dead pigs, but also healthy cull sows. Involved actors only traded and processed diseased/dead pigs and cull sows. Their counterparts in the healthy-pig trade network may have knowledge of their business and even their contacts in order to introduce farmers when needed. However, professional actors in the healthy chain had never worked with prigs because they privileged keeping their high reputation. When farmers first inquired about selling sick pigs, they consulted either neighboring farmers, customary middlemen for healthy pigs, or slaughterhouses for sick-pig buyers' contacts. When they gained experience in selling sick pigs, they called the buyers directly.

\section{Selling sick pigs: a common farmers' practice}

Farmers from $71 \%$ of small farms and $60 \%$ of large farms declared selling sick pigs. Selling sick/dead pig carcasses at a low price was

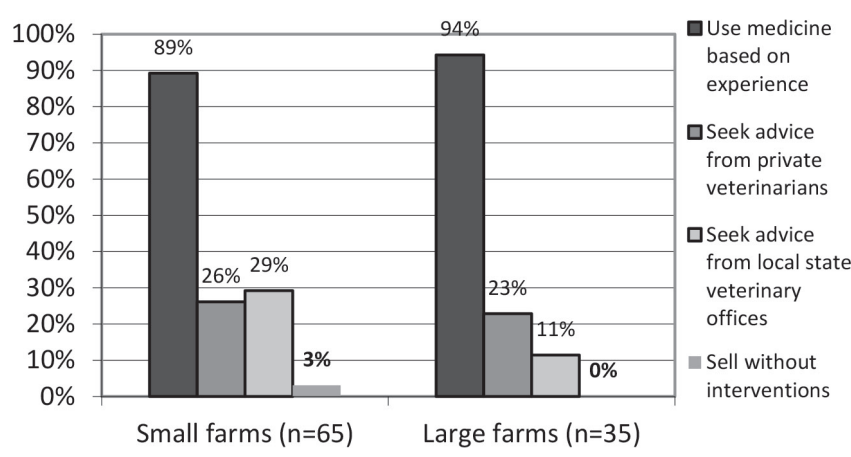

Figure 3: Farmers' actions with regard to pigs showing sickness symptoms in Hung Yen Province, Vietnam. a way to get back part of their invested capital and not face complete loss, and more compellingly it was a faster solution to get rid of carcasses (compared to declaring pig death to local state veterinarians). Most of the small (89\%) and large (94\%) farms handled their pigs without advice from the local state veterinarians. A larger proportion of small farm owners (29\% versus $11 \%$ large farm owners) contacted the local state veterinarians in case of pigs getting sick. However, a similar proportion (23-26\%) consulted local private veterinarians. Two out of 65 small farm owners declared selling sick pigs immediately without applying any treatments, however, none of large farm owners chose this option (Figure 3). Among 100 farmers' interviews, baseline mortality of swine herds ranged between $3 \%$ and $10 \%$ of total pig losses every year. Diseases or syndromes such as diarrhea, pneumonia, PRRS and pneumonic pasteurellosis were the most frequently cited (Figure 4).

Management of dead pigs varied according to the age and weight of the animals (Figure 5). Most farmers (69\% of small farms and 57\% of large farms) declared burying dead piglets (15-30 kg) far away from piggeries. Most farmers declared selling their growers to buyers who only purchased sick pigs (62\% and 57\% of small and large farms,

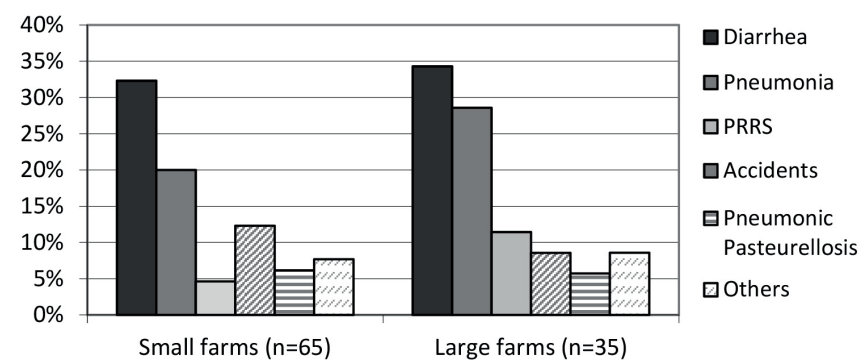

Figure 4: Main pig diseases reported by the farmers in Hung Yen Province in Vietnam.
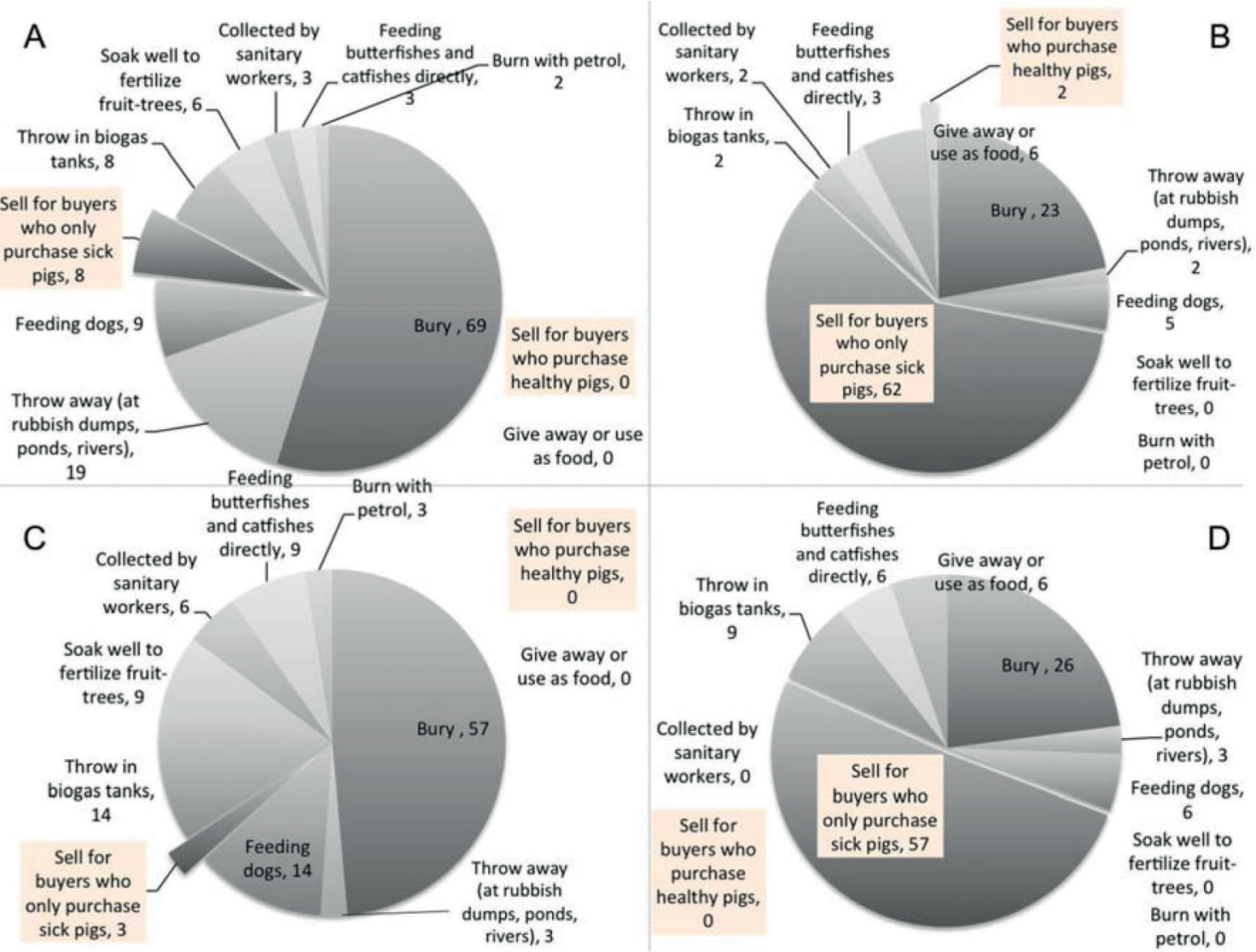

Figure 5: Management of dead pig carcasses by farmers in Hung Yen Province in Vietnam; small farms (A) sick piglets and $(B)$ sick growers; large farms (C) sick piglets and (D) sick growers. 
respectively). Only $2 \%$ of small farmers declared selling sick pigs to buyers who also purchased healthy animals. More than half of the farmers refused to provide information about the end destination of sick and dead pig carcasses (Figure 6). Information on sick-pig consumption is highly sensitive because of the illegal nature of the sick-pig trade. The interviewed farmers knew that to reveal this type of information may cause both middlemen and swine butchers to incur legal sanctions, and this would discontinue a most profitable business if their farms were to face sick/dead pigs in the future. Besides the identity of middlemen, $39 \%$ of the farmers named village X (unpublished address in My Hao) and 20\% of them named two specific sick-pig slaughterhouses in village Y (in Van Giang) as slaughterhouses for sick/dead pigs. Later interviews with these designated slaughtering units confirmed their professional operations with well-equipped slaughtering systems, freezing machines, full-time and occasional workers, and a flexible network of middlemen. Finishing products were frozen and delivered to consuming destinations (Figure 2).

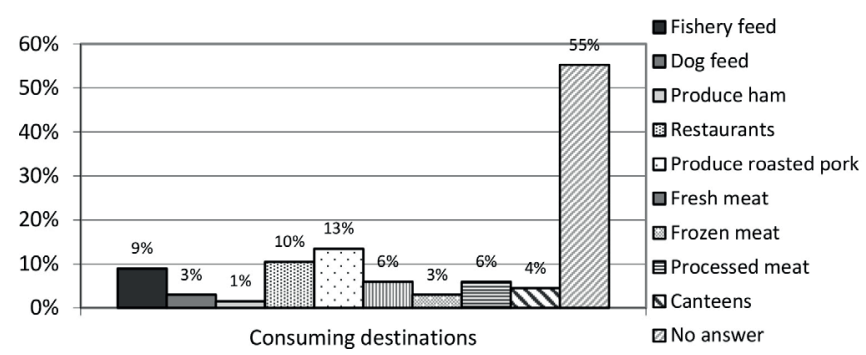

Figure 6 : Responses of the farmers, who confirmed their involvement in the sick-pig trade $(n=67)$, on the end destination of sick/dead pig carcasses in Hung Yen Province in Vietnam.

\section{The concealed activities of middlemen}

In the studied areas, farmers identified specific middlemen who always connected them with large slaughterhouses specialized in sick/dead pig and cull sow processing. These intermediate actors tended to conceal their trafficking because slaughtering, trading and improper disposal of dead animals and/or living animals showing disease symptoms are officially banned according to article No. 25 of the Law on Veterinary Medicine dated June 19, 2015 (Vietnamese National Assembly, 2015). Furthermore, sick-pig middlemen were not inclined to reveal details on the process in order to avoid domino effects on their business network, which made significant profits. In general, sick/dead pigs were treated and classified based on meat appearance. Nice-looking but diseased pork was amalgamated with healthy pork and sold to customers without their knowledge. Interviewing and collecting data from these middlemen was difficult because of the very sensitive nature of the trade. Ten middlemen were contacted during the survey but only two (from Yen My and My Hao) agreed to provide information.

Although the quantity of interviews with middlemen did not meet the initial plan, the information obtained was valuable and homogenous. Middlemen's main activity was crop farming, however occasional sick/dead pig business brought them an important source of revenue. They confirmed their role in connecting farmers and large sick/dead pig slaughterhouses. They earned revenues from sharing information on sick-pig outcome possibilities (paid by slaughterhouses $11-15 €$ per successful transaction) and from trading sick/dead pigs themselves. Middlemen paid $0.5 €$ per kilogram of sick pigs and sold them to large sick/dead pig slaughterhouses at double the price. Sick pigs were generally transported by motorbike with a capacity of 1-2 pigs per trip (possibly increased with a handmade steel trailer). In most cases, middlemen transported live sick pigs to the slaughterhouses. In some cases when the pigs were about to die, farmers and/or middlemen would cull them and get rid of their blood and internal organs to prevent the meat from darkening. Unlike professional vans that delivered healthy pigs, sick-pig middlemen's vehicles were reported to be rarely washed and decontaminated.

\section{Inclusive allocating network of slaughterhouses}

Eight slaughterhouses with contact details were mentioned by interviewees, among those we could not interview one of them because of the owner's unavailability during the field trip period. In all cases, hired workers did not accept to participate in the survey but suggested direct contacts with slaughterhouse owners. The interviews were thus solely carried out with the involvement of the slaughterhouse owners.

Slaughtering was divided into two categories: small and large slaughterhouses, characterized by the business scale and regular practices. Small slaughterhouses operated as family businesses, often including only two owners/workers as family members (mostly husband and wife). These small slaughterhouses did not have separate slaughtering areas but used their own house. They earned their living by slaughtering mainly healthy fattening pigs, sometimes cull sows and/or sick pigs which produced good-quality meats. Large sick-pig slaughterhouses operated more professionally, and comprised the owners with 5-7 workers, who were assigned to separate tasks such as slaughtering, separating organs, classifying meat, delivering, cleaning. The large sick-pig slaughterhouses worked specifically on sick/dead pigs and cull sows. Similarly to most slaughterhouses that handled healthy pigs, many sick/dead pig slaughterhouses were located close to water points (e.g. ponds, lakes, rivers). They typically included a main house, a large front yard or backyard, and were equipped with highvolume refrigerators and/or large cold rooms. After treatment and classification, the sick/dead swine meat and by-products were distributed to processing houses, retailers, common restaurants, cafeterias of companies, etc. Figure 6 shows the destination of the products from sick or dead pig carcasses according to the farmers.

\section{Sick-pig by-product processing practices}

A fish farmer and a leather manufacturer who purchased or collected parts other than pork meat were interviewed. For the leather producer, the sources of raw materials (e.g. skin, small pieces of conjunction parts, intestines) originated both from healthy and sick pigs. However, the price of by-products from sick pigs was considerably lower. The fish farmer purchased spoiled dead pigs to process animal feed at the price of $1-3$ euros $(€)$ per adult pig and $0.5-1 €$ per weaning pig. The meat of the pigs was ground, processed and blended with other materials in his house, then distributed to many carnivorous animal farms. The processing formulation was not shared.

Two interviewed farmers practiced integrated farming systems of swine and fish. Beside piggeries, they owned $1000-2000 \mathrm{~m}^{2}$ of pond areas to raise catfish and/or butterfish at the density of 10-15 fish/ $\mathrm{m}^{2}$. The raw meat of dead pigs and placentas were cut into small pieces and directly thrown into the fish ponds without being cooked or processed. Twenty kilograms of pig meat could be consumed in 1-2 hours by the fish.

\section{Driving force of the sick-pig value chain on economic aspects}

The existence and operation of this chain were mainly driven by the farmers' demand in reducing financial loss in swine farming and connecting partners, who took advantage from cheap swine products to gain considerable profits. In the studied pig farms, the average loss rate in large farms was $5-10 \%$, whereas in small and medium farms it was below 3\%. It could be seen that even if fattening pigs died when they were small, the farmers' financial loss was still significant 
because of the costs of purchasing breeding piglets (18-40 €/piglet) and feeds $(10-11 € / 25 \mathrm{~kg})$. As the investment cost in pig farming was high and maximum profits could be only $20-25 \%$ after six months of farming, farmers sold sick and/or dead pigs to recuperate part of this cost.

Regarding trading actors, both middlemen and workers in slaughterhouses, earned noteworthy earnings. The price of healthy commercial pigs, low-reproductive cull sows, old sows, diseased and dead pigs, and spoiled pigs was found to be regulated by the market demand for pork (Figure 7). Cull sows were slightly cheaper than healthy finishing pigs, but diseased/dead pigs were five times cheaper. When pigs had just died in an accident without any disease symptoms, this price could be doubled. The price of sick/dead pigs mainly depended on meat appearance, and on the pig weight and the moment of death. This business seemed to bring slaughterhouses profits via many diverse finishing products, including pork meat, bones, internal organs, skins. Meat and bones from sick pigs mixed with healthy products were sold at a slightly cheaper price. Details on the financial aspects of this chain were not shared. The demand for animal feeds using meat from spoiled dead pigs, viscera parts and the remaining protein waste from slaughtering activities was considerable. Actually, crocodile farming had been developing widely in Hai Duong (Kinh Mon District), Hai Phong and other Northern provinces, and it used protein waste from the swine commodity chains as its main feeding material.

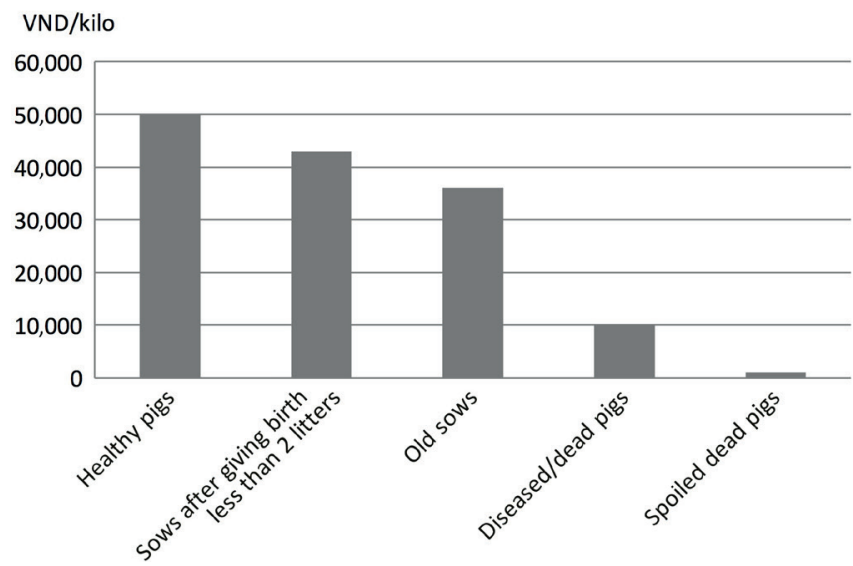

Figure 7: Average price (in 2016) of healthy pigs, reformed sows, and diseased and dead pigs in Hung Yen Province in Vietnam.

\section{- DISCUSSION}

\section{The sick-pig trade causes a risk for animal disease spread}

\section{Risks for disease spread from animal to animal}

The risk level for disease dissemination from each actor in the sick-pig trade network was evaluated through the number of links with other actors, the amount of input and output products, and the potential hazards caused by the activities. Thus, the most hazardous actors were large slaughterhouses for sick pigs and cull sows, small slaughterhouses, middlemen for sick pigs and cull sows, and sick-product retailers. Among them, despite the fact that distributors (most commonly reported as workers in large slaughterhouses or owners of small slaughterhouses) appeared to be at a busy crossroad, which linked all slaughterhouses to consuming destinations, they actually carried a lower risk of disease dissemination to animal farms because transportation routes were set apart. The highest risk of disease dissemination occurred in small slaughterhouses, followed by large sick-pig slaughterhouses and sick-pig middlemen, given the nature of their daily activities. Obviously, the activities of small slaughterhouses interacted with many other actors, not only in the sick animal chain but also in the healthy chain. Regarding middlemen, the possibility of disease transmission was mainly suspected to concern their transporting activity (Figure 2).

The likelihood of disease transmission caused by the sick-pig illegal trade is seriously considered during the occurrence of highly contagious diseases such as PRRS and pneumonic pasteurellosis. Disease dissemination was evaluated via the possible transmission of infectious microorganisms by sick pigs from infected farms to noninfected farms within the same village, or cross-contamination from village level, to district level, and beyond. There are many examples of outbreak-spread damages between countries, e.g. the recent African swine fever (ASF) outbreak which has been spreading throughout China since August 2018 (FAO, 2019). Since then, a series of actions have been taken by the Chinese Government such as setting up epidemic and buffer zones, strictly restricting movements of live pigs, releasing an 'Implementation Plan'. Due to these drastic campaigns, the number of ASF outbreaks in villages reported in China has decreased impressively from December 2018 to January 2019, leading to quarantine lifting in 97 epidemic zones in February 2019 (source: Veterinary Bureau, MARA, China) (FAO, 2019). The epidemiological studies on these campaigns revealed that the main reasons for ASF virus spread were vehicles and workers who did not use disinfectants (46\%), followed by swill feeding (34\%) and transportation (19\%) of live pigs or their products across regions (FAO, 2019).

However, in the sick-pig network, biosecurity has been lacking, especially during trading activities. Firstly, traders often came inside swine houses to assess the quality of pigs without wearing biosecurity outfits. They probably carried infectious pathogens into many farms, from village to village... Secondly, the most commonly used vehicles for carrying diseased pigs were motorbikes with unprotected handmade racks. This type of vehicle was not able to stop blood/ waste from sick animals to drop along roads, triggering disease transmission on a large scale. Moreover, carriers did not usually disinfect their trailers. According to our interviewees, biosecurity was neither required by farmers who sold sick/dead animals, nor were vehicles routinely checked. A sick/dead-pig carrier would not pass interprovincial quality checkpoints if he happened to meet one. However, all middlemen were native locals whose business took a huge advantage on their understanding of local traffics and villagers. According to FAO, middlemen such as carriers play a key role in disease transmission, and thus need thorough training in biosecurity (Madec et al., 2010). However, generally in Vietnam, these actors in both healthy and unhealthy pig chain never heed the risk of disease spread possibly caused by them because it does not immediately affect their earnings.

If pigs in a random farm are unfortunately contaminated, the middlemen will just avoid that farm and work with other ones. In healthy farms, middlemen are mostly asked to wear biosecurity outfits (e.g. clothes, shoes, gloves) by the owners. However, when swine farms are plagued by a disease, the farm owners do not act strictly with middlemen with regard to disease prevention because they prefer to sell the sick pigs as quickly as possible. This situation highlights the role of middlemen in disease transmission from animal to villages, all the way across borders between countries.

The incautious activities of middlemen also bring the risk of disease transmission by intermediate airborne animals, most commonly flies. Based on flies' traveling ability, they can spread contagious agents from pig to pig within a radius of 12 kilometers (Meerburg et al., 2007). With middlemen's motorbikes, the distance can be 100-200 kilometers. The Arterivirus causing PRRS was shown to live up to six 
hours in flies (Musca domestica) and 12 hours in fly intestines after contact from piggeries or infected meat (Otake et al., 2003a; Otake et al., 2003b).

At farm level, disease pathogens were more intensely controlled after selling sick/dead pigs when all the swine herd had been affected than in farms with partially affected herds. After selling the whole swine herd, maximum sanitary doses were applied to the entire farming area. Farmers sprayed the area with commercial products containing disinfection chemicals such as chloramine B, iodine, glutaraldehyde, sodium hydroxide, at concentrations of 2-5\% according to the manufacturer. They then applied liquid calcium hydroxide over the walls and floors and kept farming houses empty for 15-20 days before introducing the next batch. Keeping pens vacant is a crucial step in air decontamination. Calcium hydroxide is widely used for virus inactivation in swine farming (Charmley et al., 1995). An appropriate concentration of calcium or sodium hydroxide (usually $2 \%$ ) has been reported to be effective in treating infectious pathogens (Turner et al., 2000). The risk of disease spread to animals in neighboring farms is thus significantly limited.

In other cases, the pigs with disease symptoms were isolated from the healthy herds and treated with drugs, then sold if not improved. Sanitation of piggeries, including washing and disinfection, was carried out at increased intensity and frequency (from once or twice a week, to once a day), while ensuring it would not poison the pigs inside. Therefore, the risk of animal-to-animal disease transmission was higher in the farms neighboring partly infected farms.

Although swill feeding is internationally a concern because of the risk of virus transmission to pigs, the use of sick-pig meat in uncooked swill in pig feeding was not reported in our interviews. This is understandable because cannibalism is unacceptable in the Vietnamese traditional perception. For this reason, cross-contamination might be occurring only in integrated farms, where the owners feed swines, fish as well as chickens. The interviews with farmers and fish pond owners confirmed that feeding catfish/butterfish with deadpig carcass was a common practice. The raw carcass was regularly thrown into the ponds without being disinfected by heating. It was commonly reported that slurry was also poured into the ponds to feed fish. Occasionally, farmers rinsed swine pens with pond water, which causes a high risk of recontamination of the remaining herds. Even when farmers were aware of this high risk and separated the use of fish ponds and fresh-water ponds, the contamination via soil absorbents and heavy rains could not be eliminated. Besides, crossfeeding possibly brings another risk for disease spread because dead fish may be cooked to feed pigs, but improper cooking does not entirely destroy infectious germs such as FMD virus, which can survive up to six months in partially cooked, cured and smoked meat products (Scudamore, 2002; Schembri et al., 2010). In 2001, in the United Kingdom, an outbreak swept through 2000 farms and affected six million animals. It was believed to have originated from swine feeds containing contaminated meat (Bourn, 2002; Scudamore, 2002).

\section{Potential risks of disease spread from animals to humans}

The hazards of virus introduction from pigs to humans via inadequately treated manure and uncontrolled circulation of sick-meat products are a major concern because of the possibility of pathogenic contamination into the human food chain and ecosystems (Madec et al., 2010). Pig-to-human disease transmission may occur from direct contact with sick animals, indirect contact with contaminated intermediate objects, and/or ingestion of undercooked contaminated foods. Direct contact with raw meat and organs of sick/dead pigs would imply a higher risk of disease transmission to slaughtering workers. However, these workers and slaughterhouse owners are aware of the risks and they always protect themselves with closed water-resistant boots, gloves and outfits. For this reason, the main risk for them may come from indirect contacts with the zoonotic germs remaining in soil, water, intermediate insects, and fomites in general. This risk also concerns other villagers who live near contaminated areas although they have not been involved in the illegal network.

Warnings on the risk of swine disease transmission to humans caused by the consumption of undercooked pork have been issued throughout the world. In a study on the potential of pathogen transmission between species, Miller et al. (2017) conclude that the parasitic pathogen transmission potential with swine was highest for humans. According to OIE, the three most important pig parasites worldwide, i.e. Trichinella spiralis, Taenia solium and Toxoplasma, carry high risks for disease transmission to humans because of improperly cooked pork (Gamble, 1997). Beside parasites, the consumption of pork containing pathogenic bacteria also causes disease symptoms in consumers. The consumption of undercooked pork was identified as an alarming hazard for Streptococcus suis meningitis and septicemia in humans in suspected cases detected in Southern Vietnam and Thailand (Hoa et al., 2011; Wangsomboonsiri et al., 2008). Human infections with $S$. suis serotype 2 have been also reported in Japan and Thailand (Chang et al., 2006; Takamatsu et al., 2008). Blending healthy-looking pork with healthy pork to increase profit may down the line cause Vietnamese housewives to put their families at risk of contamination from the meat. Fortunately, homemade dishes are generally processed with the highest level of biosecurity with regard to cooking conditions. However, the common eateries in Vietnam, where customers can buy a full meal at a cheap price (around 0.7$1.2 €$ ), and the companies' cafeterias, where workers are provided free meals, are unlikely to meet food-safety regulations relative to cooking, including material supplying sources and food quality. The ignorance of different actors along the food chain, including the food sale links, is also believed to put public health at risk (Nguyen-Viet et al., 2017). Moreover, human exposure to virulent S. suis strains through contact with raw meat at high ambient temperature in open street markets was reported in Southern Vietnam (Hoa et al., 2011), which represents a considerable hazard for fresh-meat butchery retailers and their customers.

\section{Sick-pig consumption raises a risk for antimicrobial resistance}

Since the last decade, one of the most serious threats for global public health raised by multinational scientists is antimicrobial resistance (AMR). The evolution of multidrug-resistant microorganisms have resulted from several factors including the overuse of antibiotics in modern medicine and of chemicals in the environment. Among these, the overdependence of global populations on antibiotic drugs in both human medicine and animal production is believed to be the main reason (Prestinaci et al., 2015). In Vietnam, the livestock industry has been suffering from the recurrence of epidemics because of inadequate hygiene commonly encountered in livestock farms. To face this issue, the administration of antibiotics to fight diseases has been the main prevention method used by farmers in Vietnam, where $70 \%$ of all common registered veterinary drugs are antibiotics (Kim et al., 2013).

In both small and large farms, when the pigs show symptoms of sickness, most times farmers administer drugs based on their experience (Figure 3). The casual administration of antibiotics without the advice from veterinarians can result in high antibiotic residues in animal products, which brings the AMR threat not only for livestock, but also for humans (WHO, 2001). In small farms, there were similar rates regarding seeking advice from private or from state veterinarians (26\% and $29 \%$, respectively), whereas owners of large farms consulted local state advice significantly less (11\%). Although all private and state veterinarians are supposed to be trained in veterinary 
medicine at university level, their counsel varies in quality. In reality, the advice from private veterinarians is sometimes biased because they have received a commission from the manufacturers. As only a low proportion of farmers in our study chose to sell untreated sick pigs (3\% in small farms and $0 \%$ in large farms), this raises the alarming issue that products from the sick/dead animal value chain contain massive amounts of medicines, among which there are probably very high amounts of residual antibiotics. According to WHO in 2016, 71\% of respondents had administered antibiotics to their livestock in the previous six months in Vietnam, which was the highest rate among all surveyed areas, including the Western Pacific region (53\%), Australia $(43 \%)$ and several other Asian countries (25-62\%). In this situation, the antibiotic remaining in foods might affect consumers and possibly promote AMR progression in general.

\section{Perspectives on the role of local authorities}

Given that the majority of pig farmers, especially owners of large farms, did not choose to consult veterinarians for advice, we investigated the role of veterinarians to understand the reasons behind this habit. Staff from veterinary state offices includes well-educated veterinarians who are capable of advising farmers with regard to disease treatments. These offices generally help to manage all poultry, cattle and swine farming health issues in a commune. They are not only in charge of reporting all farming health issues to higher administrative levels (district veterinary station and province veterinary department), but also of implementing official epidemic control programs in some areas. Their services are free. However, because of the generalized and diversified nature of their missions, they cannot always help swine farmers individually in a timely manner. Alternatively, prescription and treatment by private veterinarians are also available but their cost is considered not cheap by farmers. Thus, farmers tended to learn from the treatments applied by veterinarians to later on apply them on their own. Furthermore, a great number of surveyed farmers said that any contact between external factors and their farms, even veterinarians, needed to be restricted in order to avoid cross contamination.

In general, the Vietnamese Government has acknowledged the operation of the sick-animal value chain and has made attempts to terminate it. In April 2017, the Notice about Reinforcing State Supervision on Transporting and Butchering Animals for Food Safety Security (No. 3005/CT-BNN-TY) was enacted, and a list of slaughterhouses that had been slaughtering sick/dead animals was publicized (MARD, 2017). Moreover, veterinary laws were amended in 2015 with the banning of all activities related to the sick/dead animal trade (Vietnamese National Assembly, 2015). However, the laws were not implemented until their release in 2017 (Decree No. 90/2017/ND-CP Guidelines for the Financial Punishments in Veterinary Medicines). Regarding local veterinary offices, they operate more strictly during outbreaks than the rest of the time. They also work efficiently at checkpoints between provinces, however, they are less vigilant within each province. This situation should be improved to restrict the illegal activities of the sick animal value chain.

The ignorance of farmers about food security suggests that training and educational courses about the dangers from disease transmission caused by selling sick/dead pigs should be frequently organized. Also, middlemen should be encouraged to attend training courses on biosecurity for transportation. Moreover, local authorities have to participate more actively in preventing the trade and consumption of diseased and dead pigs by controlling dead/sick-pig transportation and slaughterhouses. Finally, effective treatment methods for diseased and dead pigs should be officially proposed, for example designing models of integrated systems (livestock-aquaculture), building proper stations for burying diseased and dead pigs, supporting the development of suitable systems for treating waste in pig farms and slaughterhouses, equipping transport vehicles with adequate protections and disinfectants.

\section{CONCLUSION}

Processing, selling, consuming diseased and dead pig has been carried on for a while and is a well-organized business in the three studied districts of Hung Yen Province. There are five major participants in the sick-pig commodity chain: pig farmers, middlemen, slaughterhouse workers, distributors, and consumers. Among them, middlemen and slaughterhouse workers were the most critical actors contributing to the potential spread of pathogenic germs from infectious farms to other places. Noticeably, small slaughterhouses appeared to play a major role in terms of disease transmission from sick farms to healthy farms, and pathogenic contamination from infected products to high-quality products. Besides, the lack of biosecurity of pig transportation vehicles of middlemen and slaughterhouses possibly caused disease transmission along the delivery process on a large scale. Although the activities of sick-pig slaughterhouses were widely known in the studied areas, it was very challenging for local authorities to control them because they collected and slaughtered diseased and dead pigs but also healthy reformed sows. The authorities will need to conduct further actions to put an end to the risk of disease transmission from animal to animal or to humans, and to the risk of AMR expansion caused by these illegal activities.

\section{Acknowledgments}

This project was performed with the French Agricultural Research Centre for International Development (CIRAD) and the Faculty of Animal Science, Vietnam National University of Agriculture (VNUA). We acknowledge the kind support of veterinary state offices in Van Lam, Van Giang and My Hao districts as well as the valuable cooperation of local village heads, farmers, swine traders and swine dealers.

\section{Author contributions statement}

The results of this research have been obtained with the contributions of all the authors. The conception and work plan were created by MP and TDV. Farmer surveys were performed by TDN, PTN and MNH. Surveys for middlemen and slaughterhouses were conducted by HQH, PTN and TDN. Data input was handled by TDN, PTN and MNH. Data analysis was carried out by $\mathrm{MNH}$ with suggestions from the other authors. The manuscript including data figures was written by MNH. Results and manuscript were reviewed and commented by TDV and MP, later edited and finalized by MNH. The manuscript was submitted and revised by $\mathrm{MNH}$, considering comments of two reviewers from CIRAD.

\section{REFERENCES}

Althouse G.C., Rossow K., 2011. The potential risk of infectious disease dissemination via artificial insemination in swine. Reprod. Domest. Anim., 46 (s2): 64-67, doi: 10.1111/j.1439-0531.2011.01863.x

Baudon E., Fournié G., Hiep D.T., Pham T.T.H., Duboz R., Gély M., Peiris M., et al., 2017. Analysis of swine movements in a province in Northern Vietnam and application in the design of surveillance strategies for infectious diseases. Transbound. Emerg. Dis., 64 (2): 411-424, doi: 10.1111/ tbed. 12380

Bourn J., 2002. The 2001 outbreak of foot and mouth disease. Report. National Audit Office, London, UK

Brouwer J., Frankena K., De Jong M.F., Voets R., Dijkhuizen A., Verheijden J., Komijn R.E., 1994. PRRS: Effect on herd performance after initial infection and risk analysis. Vet. Q., 16 (2): 95-100, doi: 10.1080/01652176.1994.9694427 
Chang B., Wada A., Ikebe T., Ohnishi M., Mita K., Endo M., Matsuo H., et al., 2006. Characteristics of Streptococcus suis isolated from patients in Japan. Jpn. J. Infect. Dis., 59 (6): 397

Charmley L.L., Trenholm H.L., Prelusky D.B., Rosenberg A., 1995. Economic losses and decontamination. J. Nat. Toxins, 3 (4): 199-203, doi: 10.1002/ nt.2620030406

Daley B.J., Cañas A.J., Stark-Schweitzer T., 2007. CmapTools: Integrating teaching, learning, and evaluation in online courses. New Dir. Adult Cont. Educ., 2007 (113): 37-47, doi: 10.1002/ace.245

Delabouglise A., Antoine-Moussiaux N., Phan T.D., Dao D.-C., Nguyen T.T. Truong B.D., Nguyen X.N.T., et al., 2016. The perceived value of passive animal health surveillance: The case of highly pathogenic avian Influenza in Vietnam. Zoonoses Public Health, 63 (2): 112-128, doi: 10.1111/ zph.12212

Desvaux S., Figuié M., 2011. Formal and informal surveillance systems: how to build bridges? In: Intl. Conf. Animal Health and Surveillance, 1. Lyon, France, 17-20 May 2011

Desvaux S., Nguyen C.-O., Vu D.-T., Henriquez C., Ky V.-D., Roger F., Fenwick S., et al., 2016. Risk of introduction in Northern Vietnam of HPAI viruses from China: description, patterns and drivers of illegal poultry trade. Transbound. Emerg. Dis., 63 (4): 389-397, doi: 10.1111/tbed.12279

FAO, 2019. ASF situation in Asia update. FAO, Rome, Italy

Feng Y., Zhao T., Nguyen T., Inui K., Ma Y., Nguyen T.H., Nguyen V.C., et al., 2008. Porcine respiratory and reproductive syndrome virus variants, Vietnam and China, 2007. Emerg. Infect. Dis., 14 (11): 1774-1776, doi: 10.3201/eid1411.071676

Gamble H.R., 1997. Parasites associated with pork and pork products. Rev. Sci. Tech. Off. Int. Epizoot., 16 (2): 496-506, doi: 10.20506/rst.16.2.1032

Hoa N.T., Chieu T.T.B., Nga T.T.T., Dung N.V., Campbell J., Anh P.H., Tho H.H., et al., 2011. Slaughterhouse pigs are a major reservoir of Streptococcus suis serotype 2 capable of causing human infection in southern Vietnam. PloS One, 6 (3): e17943, doi: 10.1371/journal.pone.0017943

Johnson C.D., Mabry J.W., Kliebenstein J.B., Neumann E., 2005. The impact of PRRS on the pig cost of production. J. Anim. Sci., 651 (1): 71, doi: 10.31274/ans air-180814-112

Kim D.P., Saegerman C., Douny C., Dinh T.V., Xuan B.H., Vu B.D., Hong N.P., et al., 2013. First survey on the use of antibiotics in pig and poultry production in the Red River Delta region of Vietnam. Food Public Health 3 (5): $247-256$

Madec F., Hurnik D., Porphyre V., Cardinale E., 2010. Good practices for biosecurity in the pig sector. FAO, Rome, Italy

MARD, 2017. Notice about reinforcing state supervision on transporting and butchering animals for food safety security. Ministry of Agriculture and Rural Development, Hanoi, Vietnam

Meerburg B.G., Vermeer H.-M., Kijlstra A., 2007. Controlling risks of pathogen transmission by flies on organic pig farms: A Review. Outlook Agric., 36 (3): 193-197, doi: 10.5367/000000007781891432

Miller R.S., Sweeney S.J., Slootmaker C., Grear D.A., Di Salvo P.A., Kiser D., Shwiff S.A., 2017. Cross-species transmission potential between wild pigs, livestock, poultry, wildlife, and humans: implications for disease risk management in North America. Sci. Rep., 7 (1): 7821, doi: 10.1038/s41598017-07336-z
Nga N.T.D., Ninh H.N., Hung P., Lapar M.L., 2013. The pig value chain in Vietnam: A situational analysis report. ILRI, Nairobi, Kenya

Nguyen T., 2013. PRRS control in the region. In: 28th Conf. OIE Regional Commission for Asia, the Far East and Oceania, Compendium of Technical Items, Cebu, Philippines, 18-22 Nov. 2013

Nguyen-Viet H., Tuyet-Hanh T.T., Unger F., Dang-Xuan S., Grace D., 2017. Food safety in Vietnam: where we are at and what we can learn from international experiences. Infect. Dis. Poverty, 6 (1): 39 doi: 10.1186/ s40249-017-0249-7

OIE, 2007. Viet Nam Report, Aug. 2007. OIE, Paris, France

Otake S., Dee S.A., Rossow K., Moon R., Trincado C., Pijoan C., 2003a Transmission of porcine reproductive and respiratory syndrome virus by houseflies (Musca domestica). Vet. Rec., 152 (3): 73-76, doi: 10.1136/ vr.152.3.73

Otake S., Dee S.A., Moon R.D., Rossow K.D., Trincado C., Farnham M., Pijoan C., 2003b. Survival of porcine reproductive and respiratory syndrome virus in houseflies. Can. J. Vet. Res., 67 (3): 198-203

Pham H.T.T., Antoine-Moussiaux N., Grosbois V., Moula N., Truong B.D. Phan T.D., Vu T.D., et al., 2017. Financial impacts of priority swine diseases to pig farmers in Red River and Mekong River Delta, Vietnam. Transbound. Emerg. Dis., 64 (4): 1168-1177, doi: 10.1111/tbed.12482

Prestinaci F., Pezzotti P., Pantosti A., 2015. Antimicrobial resistance: a global multifaceted phenomenon. Pathol. Glob. Health, 109 (7): 309-318, doi: 10.1179/2047773215Y.0000000030

Schembri N., Hernández-Jover M., Toribio J.A., Holyoake P.K., 2010. Feeding of prohibited substances (swill) to pigs in Australia. Aust. Vet. J., 88 (8): 294-300, doi: 10.1111/j.1751-0813.2010.00604.x

Scudamore J. M., 2002. Origin of the UK foot and mouth disease epidemic in 2001. Department of Environment, Food and Rural Affairs, London, UK

Takamatsu D., Wongsawan K., Osaki M., Nishino H., Ishiji T., Tharavichitkul P., Khantawa B., et al., 2008. Streptococcus suis in humans, Thailand. Emerg. Infect. Dis., 14 (1): 181, doi: 10.3201/eid1401.070568

Tian K., Yu X., Zhao T., Feng Y., Cao Z., Wang C., Hu Y., et al., 2007. Emergence of fatal PRRSV variants: unparalleled outbreaks of atypical PRRS in China and molecular dissection of the unique hallmark. PloS One, 2 (6) e526, doi: 10.1371/journal.pone.0000526

Turner C., Williams S.M., Cumby T.R., 2000. The inactivation of foot and mouth disease, Aujeszky's disease and classical swine fever viruses in pig slurry. J. Appl. Microbiol., 89 (5): 760-767, doi: 10.1046/j.13652672.2000.01174.x

Vietnamese Government, 2017. Guidelines for the financial punishments in veterinary medicines, 31 Jul 2017, Hanoi, Vietnam

Vietnamese National Assembly, 2015. Law on Veterinary Medicine, 19 June 2015, Hanoi, Vietnam

Wangsomboonsiri W., Luksananun T., Saksornchai S., Ketwong K., Sungkanuparph S., 2008. Streptococcus suis infection and risk factors for mortality. J. Infection, 57 (5): 392-396, doi: 10.1016/j.jinf.2008.08.006

WHO, 2001. Monitoring antimicrobial usage in food animals for the protection of human health, Oslo, Norway, 10-13 Sept. 2001. WHO, Geneva, Switzerland

WHO, 2016. National Action. The riding tide for global change on antimicrobial resistance. WHO, Geneva, Switzerland 


\section{Résumé}

Hoang M.N., Nguyen P.T., Han H.Q., Nguyen T.D., Vu T.D., Peyre M. Analyse du réseau de la filière des porcs malades dans le nord du Vietnam : risque de diffusion de la maladie

Une étude a été menée entre janvier et juillet 2016 pour enquêter sur le réseau de commerce de porcs malades qui serait en activité dans le nord du Vietnam depuis des décennies. Depuis début 2015, de nombreux avertissements sur l'existence de ce réseau illégal ont été publiés dans les journaux locaux, ce qui a suscité une grande inquiétude chez les consommateurs et les autorités. L'objectif de cette étude était d'enquêter sur la filière pour identifier le réseau commercial, évaluer le risque de diffusion de la maladie et proposer des solutions préventives. Les résultats ont montré que la chaîne de production des porcs malades comprenait des agriculteurs, des intermédiaires, des abattoirs et des consommateurs dans les trois districts étudiés (Van Lam, Van Giang et My Hao, dans la province de Hung Yen). L'évaluation qualitative des risques a déterminé que les intermédiaires et les abattoirs étaient les acteurs principaux de cette filière non contrôlée. Une réglementation administrative appropriée, indépendamment de I'importance de ces acteurs, serait cruciale pour limiter les effets négatifs des produits issus de porcs malades. En outre, une intervention adaptée ôterait les menaces pesant sur les autres élevages et éviterait les effets à long terme sur la santé humaine.

Mots-clés : porcin, chaîne d'approvisionnement alimentaire, évaluation du risque, maladie des animaux, fraude, Vietnam

\section{Resumen}

Hoang M.N., Nguyen P.T., Han H.Q., Nguyen T.D., Vu T.D., Peyre M. Análisis de la red de la cadena de productos de porcinos enfermos en el norte de Vietnam: riesgo de diseminación de enfermedades

Entre enero y julio de 2016 se realizó un estudio para investigar la red de comercio de cerdos enfermos que supuestamente ha estado en funcionamiento en el norte de Vietnam durante décadas. Desde principios del 2015, los periódicos locales han publicado numerosas advertencias sobre la existencia de esta red ilegal, generando una gran preocupación por parte de los consumidores y las autoridades. El objetivo de este estudio fue investigar la cadena de productos para identificar la red comercial, evaluar el riesgo de diseminación de enfermedades y proponer soluciones preventivas. Los resultados mostraron que la cadena de productos provenientes de cerdos enfermos incluía agricultores, intermediarios, mataderos y consumidores en los tres distritos estudiados (Van Lam, Van Giang y My Hao, en la provincia de Hung Yen). La evaluación de riesgos cualitativos determinó que los intermediarios y mataderos eran los actores centrales en esta cadena de cuantía descontrolada. Regulaciones administrativas adecuadas, independientemente de la importancia de estos actores, serían cruciales para limitar los efectos negativos de los productos de cerdos enfermos. Aún más, una intervención adecuada evitaría amenazas a otras fincas ganaderas y efectos a largo plazo en la salud humana.

Palabras clave: cerdo, cadena de suministro alimentario, evaluación de riesgos, enfermedades de los animales, fraude, Vietnam 